\title{
T-Kininogen Measurement
}

National Cancer Institute

\section{Source}

National Cancer Institute. T-Kininogen Measurement. NCI Thesaurus. Code C132387.

The determination of the amount of T-kininogen in a biological sample. 